\title{
Study of Working Experience in Remote Rural Areas after Medical Graduation
}

Thapa KR, ${ }^{1}$ Shrestha BK, ${ }^{2}$ Bhattarai MD ${ }^{1}$

${ }^{1}$ Department of Medicine

National Academy of Medical Sciences

Bir Hospital, Kathmandu, Nepal

${ }^{2}$ Manmohan Memorial Medical College and Teaching Hospital

Kathmandu, Nepal

\section{Corresponding Author}

Madhur Dev Bhattarai

Department of Medicine

National Academy of Medical Sciences

Bir Hospital, Kathmandu, Nepal

E-Mail:mdb@ntc.net.np

\section{Citation}

Thapa KR, Shrestha BK, Bhattarai MD. Study of Working Experience in Remote Rural Areas after Medical Graduation. Kathmandu Univ Med J 2014;46(2):121-5.

\section{ABSTRACT}

\section{Background}

Posting of doctors in remote rural areas has always been a priority for Government; however data are scarce in the country about experience of doctors of working in remote areas after medical graduation.

\section{Objective}

A questionnaire survey of doctors was planned to analyze their experience of working after graduation in remote rural areas in various parts of the country.

\section{Method}

The cross-sectional survey was done by convenience sampling method. A one-page questionnaire with one partially closed-end and five open-end type questions was distributed to the doctors who had worked in remote rural areas after graduation under various governments' postings.

\section{Result}

Two-third of participants had their home in urban areas and $89.8 \%$ had stayed for 1 to 5 years. About half of the participants had difficulty in getting the posting in the remote areas of their choice. Most participants indicated provision of opportunities for Residential (postgraduate) Training as their reasons of going to remote areas as well as their suggestions to encourage young graduates to go there. Similarly most also suggested appropriate career, salary and incentives to encourage doctors to go to work in remote areas. About $85 \%$ of participants pointed out the major problem faced while posted in remote areas as difficulty in handling varied situations with no guidance or seniors available around.

\section{Conclusion}

The notable points indicated by the participants are centered on the opportunity for Residential Training and difficulties faced without such training. Residential Training is a priority to be considered while planning the health policy for optimum health care of people.

\section{KEY WORDS}

Health service, medical graduate, postgraduate training, remote area health, residential training, rural health, rural retention. 


\section{INTRODUCTION}

The access to optimum basic health care is the fundamental right of the people. The health coverage of the population, especially rural one, is still inadequate in the developing countries. How to ensure people living in rural and remote locations have access to trained health workers has rightly been a real concern. ${ }^{1}$ Thus, the posting of medical doctors in remote rural areas has always been a priority for the Government. However, from the perspective of the training of the medical doctors, completing structured Residential, commonly called here Postgraduate, Training in a specialty is the priority after medical graduation. ${ }^{2-5}$ The crucial incentive for Bachelor of Medicine and Bachelor of Surgery (MBBS) graduates is the programme to provide Residential Training opportunities. ${ }^{2}$ Data are scarce in the country about the relation of the two such priorities viz. the posting of medical graduates in remote rural areas from the perspectives of Government and Residential Training from that of medical graduates. There are studies of medical students' characteristics and intentions with or without later practice locations in the country as well as of other researches, commentaries and review on health coverage and medical education and training. ${ }^{4-16}$ However the reports about the difficulties and suggestions of the medical doctors with experience of working in the remote rural areas after MBBS are scarce.

There is provision of giving extra marks for the work experience in remote rural areas for enrollment in a postgraduate institute in the country since 2002. ${ }^{17}$ The extra marks for enrollment in the Residential Training programme are given according to the remoteness of the areas posted as per the classification of the remote areas by the regulation of the Government. The remote areas in the country are divided into very-remote (Ka 1 and Ka 2), remote (Kha 1 and Kha 2), and not- remote (Ga 1 and Ga 2) areas. In each of these three categories, the designation 1 is relatively more remote than 2 . For experience of working for six months in each of these categories and subcategories, the marks awarded are 5, 4.5, 4, 3, 2.5, and 1.5 from very-remote to not-remote areas respectively (from Administration section, Ministry of Health and Population, June 2013). The extra marks for the work experience in the remote areas for enrollment in the Residential Training programmes are given up to maximum 20. ${ }^{17}$ Minimum 12 mark is required to apply for study in the regulations. In these backgrounds, a questionnaire survey of medical doctors was planned to analyze their reasons for going to remote rural areas in various parts of the country earlier as medical officers after MBBS and their difficulties and suggestions.

\section{METHOD}

A cross-sectional questionnaire survey of doctors about their working experience in remote rural areas in different parts of the country after MBBS along with their suggestions was conducted. The doctors who had worked in remote rural areas from the year 2002 to June 2013 were considered eligible for inclusion in the study and the questionnaires were distributed and collected from June 2013 to December 2013 by convenience sampling method. The number of newly appointed permanent medical officers with MBBS posted in various remote rural areas from the year 2002 till June 2013 was 442 (from Administration section, Ministry of Health and Population, June 2013). In the study, the number of the participants was planned to be at least one-fourth of the total numbers of the newly appointed permanent medical officers posted in various districts during that period from 2002 to June 2013. Medical doctors who graduated under government scholarships are also required to serve under the government postings for two years. They were also included in the study. A one-page questionnaire with six points was distributed for voluntary participation to those medical doctors who had worked in the remote rural areas under various postings of the government. The following six points were covered in the questionnaire:

1. Your home: Urban or rural area

2. Why did you go to remote areas for work after MBBS?

3. Could you easily get the posting in the remote area?

4. How long did you stay?

5. The problems faced as a medical officer while in the remote posting

6. Suggestions to encourage medical graduates to go to work in remote areas.

The first question was partially closed-end type. The rest of the questions were open-end type to allow for spontaneity of the response. The questions were constructed to gather information without leading them for any particular response. The questions were presented in the paper format, so that there was no interviewer bias.

\section{RESULT}

In the survey, there were total one hundred twenty seven participants. The number of the participants in the survey is about one-third of the total numbers of the newly appointed permanent medical officers posted in various districts in the last one decade. Among the participants, $66.1 \%$ had their home in urban areas and $33.9 \%$ in rural areas. Of the total participants, $42.5 \%$, had difficulty in getting the posting in the remote areas of their choice or with high marks for Residential Training Entrance. The frequency of duration of working in the remote rural areas as medical officers by the participants is shown in the Table 1. All the participants worked for more than one year in remote rural areas with about $90 \%$ from one to five years. The responses to other questions, which were open-ended ones, were multiple. They were grouped into common headings. The frequency of major groups of the common 
Table 1. The frequency of duration of working in the remote rural areas after MBBS by the participants

\begin{tabular}{lc|}
\hline Duration of working in the remote rural areas* & $\begin{array}{c}\text { Percentages of } \\
\text { response }\end{array}$ \\
\hline For 1 to 2 years & $32.3 \%$ \\
\hline For 2 to 3 years & $33.1 \%$ \\
\hline For 3 to 4 years & $15.0 \%$ \\
\hline For 4 to 5 years & $9.4 \%$ \\
\hline For more than 5 years & $10.2 \%$ \\
\hline Total & $100 \%$ \\
\hline
\end{tabular}

*All the participants had worked for more than 1 year.

reasons of going to remote rural area to work is given in the Table 2. Two-third of the participants had gone to remote areas for getting higher marks for Residential Training admission. The frequency of major groups of the

Table 2. The frequency of major groups of the common reasons of going to remote rural areas to work after MBBS

\begin{tabular}{|lc|}
\hline Major reasons of going to remote rural areas* & $\begin{array}{c}\text { Percentages of } \\
\text { response }\end{array}$ \\
\hline Getting higher marks for postgraduate admission & 66.1 \\
\hline As a part of government service & 48.0 \\
\hline Serving rural people & 28.4 \\
\hline Getting experience of remote areas & 18.9 \\
\hline *Multiple responses & \\
\hline
\end{tabular}

common professional problems faced while in the remote rural posting after MBBS is shown in Table 3. About $85 \%$ of the participants indicated the major problem faced while posted in remote rural areas as difficulty in handling varied situations with no guidance or seniors available around. Lack of adequate facilities was other common major problem

Table 3. The frequency of major groups of the common professional problems faced while in the remote rural postings after MBBS

\begin{tabular}{|lc|}
\hline Major groups of the problems faced* & $\begin{array}{c}\text { Percentage of the } \\
\text { response }\end{array}$ \\
\hline $\begin{array}{l}\text { Difficulty in handling varied situations } \\
\text { No guidance or seniors available around }\end{array}$ & 83.7 \\
\hline Lack of adequate facilities, including internet & 80.3 \\
\hline Political pressure & 25.2
\end{tabular}

*Multiple responses.

faced. Table 4 shows the frequency of the major groups of the common suggestions of the participants to encourage doctors with MBBS to go to work in remote rural areas. About $80 \%$ of the participants indicated opportunities for postgraduation as the suggestion to encourage doctors to go to work in remote rural areas. Other common suggestions were adequate salary and incentives, appropriate career and postings, and improvement of facilities.
Table 4. The frequency of the major groups of the common suggestions to encourage doctors with MBBS to go to work in remote rural areas

\begin{tabular}{|lc|}
\hline Major groups of the suggestions* & $\begin{array}{c}\text { Percentages of the } \\
\text { response }\end{array}$ \\
\hline Opportunities for postgraduation & 77.2 \\
\hline Adequate salary and incentives & 70.1 \\
\hline Appropriate career and postings & 60.6 \\
\hline Improvement of facilities & 52.0 \\
\hline *Multiple responses & \\
\hline
\end{tabular}

\section{DISCUSSION}

In this study of doctors who had gone to remote rural areas after MBBS, almost two thirds had their home in urban areas. This is in contrast to a report of doctors graduated from 1983 to 2004 from Nepal's first medical college where rural birth place was associated with a doctor working outside the capital city of Kathmandu. ${ }^{6}$ In that study when there were relatively less number of doctors in the country, the main outcome measure was the career practice location and as the authors pointed out the relation was with the working outside Kathmandu city, not purely rural. ${ }^{6}$ On the contrary, though the experience of working in our study was in the remote rural areas itself, the working was mostly for some years only under different postings of the government. In a study of perception about working in rural areas in future after graduation, though most medical students were from urban areas, $72.4 \%$ indicated they would work in rural areas after graduation. ${ }^{7}$ In another study of medical students, more than $80 \%$ agreed to the statement that 'I have a duty to the people of Nepal to practice in Nepal'. ${ }^{5}$ Such intention is seen in other study as well. ${ }^{4}$ Further doctors in Nepal have had been graduating from different parts of the world. In a report of doctors graduated till 2000, nearly $38 \%$ doctors were trained in India, 22\% each from former USSR and Nepal, 10\% from Bangladesh, and $2.5 \%$ from Pakistan with rest few from other countries and nearly two-third of the doctors were from the central developmental region and most of them were from Kathmandu valley. ${ }^{11}$ Moreover the situation of the medical education has also changed now rather rapidly. As of early 2011, there were total eighteen medical colleges functioning inside Nepal with more than $50 \%$ outside Kathmandu for medical graduation. ${ }^{9}$ There are about 1800 first year medical students, including foreign students, enrolled in the medical colleges in various parts of the country inside and outside the capital city Kathmandu. ${ }^{9}$ Now with such mix of the increasing number of medical doctors from various parts of the country graduating from the medical colleges situated in different places inside or outside the country, the origin of the medical doctors alone may not matter much for their settlement later. Further there is increasing urbanization and transport facilities as well as competition and need of specialization. With the appropriate intention, as discussed above, of the medical 
professionals, the training opportunities, income and career systems available will play much significant role. The recent trend of migration to and settlement in any places inside or outside the country observed in various other manual or professional occupations indicates similarly. In a study of medical professionals with Residential Training of Doctor of Medicine in General Practice (MDGP) in Nepal, the health assistant background and undergraduate rural exposure were also not found to be significant in determining the location of work. ${ }^{8}$

In the present study, almost half of the participants had difficulty in getting the posting in the remote areas of their choice or with high marks for Residential Training entrance. Almost two third of them also indicated appropriate career and postings as their suggestions to encourage doctors to go to work in remote areas. These points indicate the need of having appropriate management system of career and postings for Government doctors. There is a mechanism of replacing doctors in any rural areas after a few years in other countries as well. ${ }^{2}$ In our study majority of the participants also indicated the lack of adequate facilities, including internet, in the remote rural postings. At least the internet facilities could perhaps be relatively easily improved with increasing availability of varieties of electronic devices and modalities. The internet facilities will help to acquire professional information by the doctors and to develop later telemedicine consultations network in a phase-wise manner. The need of telemedicine was also pointed out by some participants in the study. Lack of support and facilities and of clear career path were also noted as the difficulties faced in rural areas in other studies in the country. ${ }^{7,8,16}$ In a study in the country the strongest theme while exploring the key issues that influence doctors' retention in rural areas was that of career development and the participant even felt 'trapped' in rural areas due to lack of appropriate arrangement. ${ }^{16}$ Similarly, in a recent study of medical students and young doctors of Nepal, serving the sick along with postgraduate course availability, salary, infrastructures and facilities, and career opportunities influenced the career choice. ${ }^{4}$ In another recent study of medical students in our country, two thirds agreed to the statement that 'Additional payments from the government would make me more likely to practice in a rural area'. ${ }^{5}$ The need of adequate salary and incentives was also pointed out by the participants in our study. The fulfillment of such need could possibly be achieved by the appropriate mobilization of the resources of vertical public health programmes, run with the help of international nongovernmental agencies, for doctors in remote areas who are also involved in supervising and achieving the targets of such programmes. ${ }^{13}$

Most of the participants in this study indicated the provision of opportunities of Residential Training as their reason of going to remote areas as well as their suggestions to encourage the medical graduates to go to remote areas pointing out the crucial role of opportunities for Residential
Training for doctors. The studies in other countries have also reported their success in matching physicians' interest in specialization with the country's needs for rural doctors. ${ }^{2}$ Most of the participants in the study also pointed out the problem faced while posted in remote areas as the difficulty in handling varied situations and no guidance or seniors available around. This is consistent with the observation made a few years back that most doctors with just graduation have problems in carrying out the necessary surgeries and procedures including the complicated delivery. ${ }^{10}$ In contrast to the difficulties faced in handling varied situations with no guidance or seniors available around by the medical graduates in our study, the lack of other specialist support was not a problem in case of MDGPs in a study in our country only. ${ }^{8}$ Many participants in our study also suggested posting of trained practitioners with MDGP in remote areas. The modern medical education concepts and trends similarly indicate the need of the residential training after the medical graduation. ${ }^{3}$ The inadequacy of undergraduate medical education to give enough confidence to practice to medical students is reported by a study of medical students in their last two years of education. Most of such senior medical students agreed they need to leave Nepal to get enough training in their field, as there are not enough Residential Training positions in Nepal for everyone who wants them. ${ }^{5}$ The authors concluded that expressing a need to leave Nepal to get sufficient medical training was associated with intent to go abroad for practice. ${ }^{5}$ There is tremendous growth of number of medical graduates in Nepal and unless there is clear policy to appropriately train, deploy and retain these doctors to serve the need of rural community, Nepal will suffer a missed opportunity to use its own human resource. ${ }^{12,15}$ In this study the practitioners themselves are expressing their difficulties in providing the optimum service without adequate training or supervision. Government's responsibility may not be fulfilled by just posting the medical graduates in remote rural areas. The importance of appropriate Residential Training and planning for their career is vital to encourage medical professionals to work in any area or field.

In summary, the most common reasons, problems and suggestion by the participants in our study are centered on the opportunity for Residential Training and difficulties faced without such training along with the need of appropriate career and incentives. The reasons, problems and suggestions expressed by the participants point out the need to facilitate the provision of Residential Training along with the appropriate career and incentives by the Government for the quality health care of the people These points need to be taken into account while planning the health policy in the context of the increasing number of medical graduates in the country and the changing concept of the medical education. The high time now to revisit, revise and reform national health policy according to the present context envisioning future challenges is recently also highlighted. ${ }^{18}$ 
There are some apparent limitations of the study to be clarified. The number of the sample may appear relatively small, but the number is about one third of the total number of permanent medical officers posted in various districts in the last one decade. The other issue is that the sample of the participants is not random or all inclusive. It is a convenience sampling, a method commonly followed in the data collection considering the resources and time for any study. The studies of experience of the key health personnel serving the remote rural areas are as such scarce in the country.

\section{REFERENCES}

1. WHO. The World Health Report: Primary Health Care - Now More Than Ever. Geneva: WHO; 2008.

2. Pena S, Ramirez J, Becerra C, Carabantes J, Arteaga O. The Chilean Rural Practitioner Programme: a multidimensional strategy to attract and retain doctors in rural areas. Bull World Health Organ .2010;88:371-8.

3. Bhattarai MD. Twenty Lessons to Incorporate EBM Concept and Practices into Medical Education. In: Sitaras NM, Ed. Evidence Based Medicine (EBM) - Closer to Patients or Scientists? Rijeka: INTECH, 2012: 29-54. (Available for free downloads at: http://www. intechopen.com/books/evidencebased-medicine-closer-to-patientsor-scientists-/)

4. Bruce HW, Shakya R. Career choices and what influences Nepali medical students and young doctors: a cross-sectional study. Human Resources for Health 2013; 11:5.

5. Huntington I, Shrestha S, Reich NG, Hagopian A. Career intentions of medical students in the setting of Nepal's rapidly expanding private medical education system. Health Policy and Planning 2011;1-12.

6. Zimmerman M, Shakya R, Pokhrel BM, Eyal N, Rijal BP, Shrestha RN, et al. Medical students' characteristics as predictors of career practice location: retrospective cohort study tracking graduates of Nepal's first medical college. BMJ 2012:345:e4826.

7. Shankar PR, Thapa TP. Student perception about working in rural Nepal after graduation: a study among first- and second-year medical students. Human Resources for Health 2012,10:27.

8. Hayes B, Gupta S. Recruitment and retention issues for Nepal's general practitioners. J Nepal Med Assoc 2003;42(147):142-7.

\section{CONCLUSION}

The most common reasons, problems, and suggestion by the participants in our study are centered on the opportunity for Residential Training and difficulties faced without such training along with the need of appropriate career and incentives. Government's responsibility may not be fulfilled by just posting the medical graduates in rural, remote areas. The priority given to the Residential Training by the participants in the study is consistent with the modern medical education concepts. These points need to be considered while planning the health policy for optimum health care of the people.

9. Magar A, Subba K. Strengthening district health care system through partnerships with academic institutions: The social accountability of medical colleges in Nepal. J Nepal Med Assoc 2012;52(187):142-7.

10. Zimmerman M. Not just any doctor - To upgrade rural healthcare, Nepal needs general practitioners. Nepali Times 27 June 2008 - 03 July 2008:406 ( (Available at http://nepalitimes.com/news. php?id=14995)

11. Thapa BK. Geographic Origin of Nepali Doctors. Kathmandu Univ Med J 2003:2(6):152-6.

12. Chaudhary SK, Chaudhary P. Maternal Health in Nepal: Exploring the Role of MDGPs in Scaling Up Emergency Obstetric and Neonatal Care Services. PG Med J NAMS 2008;8(1):134-9.

13. Bhattarai MD. PG medical training and accreditation: Responsibility of the Government for the adequate health service delivery. Nepal Med Coll J 2012;14(3):256-62.

14. Shankar PR. Attracting and retaining doctors in rural Nepal. Rural and Remote Health 2010;10:1420 (Online).

15. Zimmerman M. Getting doctors to stay -Nepal's health care system is crying out for change. Nepali times 04 May 07 - 10 May 07:347. (Available at www.nepalitimes.com)

16. Butterworth K, Hayes B, Neupane B. Retention of general practitioners in rural Nepal: A qualitative study. Australian J Rural Health 2008,16: 201-6.

17. Sharma VK. Glimpses of postgraduate teaching programs of Nepal. PG Med J NAMS 2008;8(1):143-51.

18. Magar A. National Health Policy of Nepal-Time to Revisit and Reform. J Nepal Med Assoc 2013;52(190):I-II 